
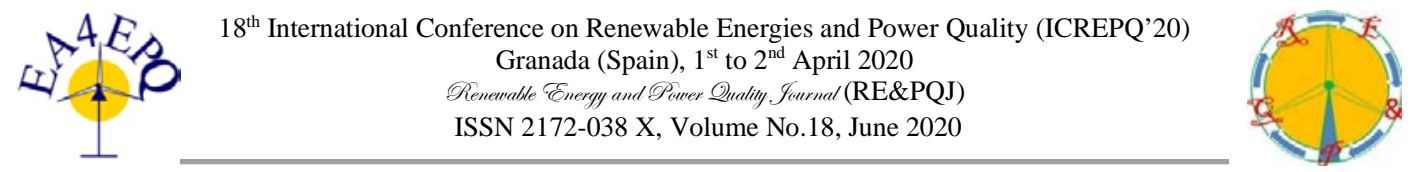

\title{
Multi-technology battery storage system for optimal demand-side management
}

\author{
E. Laporta ${ }^{1}$, G. Fernández ${ }^{1}$, E. García ${ }^{1}$, J.M. Perié ${ }^{1}$, M.A. Alonso ${ }^{1}$ \\ and J. Berges ${ }^{1}$ \\ ${ }^{1}$ Electrical Systems Area \\ CIRCE Foundation, Zaragoza (Spain) \\ e-mail: elaporta@fcirce.es gfa@fcirce.es egarcia@fcirce.es imperie@fcirce.es maalonso@fcirce.es \\ iberges@fcirce.es
}

\begin{abstract}
Demand-side management (DSM) provides additional system flexibility for the electric energy environment. To enable the spread of DSM policies the use of automatic systems combined with a local battery energy storage system (BESS) is proposed. Following this statement, it has been developed and tested a $50 \mathrm{kVA}$ low-cost multi-technology energy storage system, with a novel converter topology that permits the integration of multiple battery types or aging. It consists of a 50 kVA bidirectional three-level AC/DC converter for grid connection which feeds five $10 \mathrm{~kW}$ isolated bi-directional DC/DC battery converters, based on SiC and Si MOSFETs. The development leads in a pick-and-place system, adding interoperability, ease of connection and modularity.
\end{abstract}

Key words. Demand Side Management (DSM), Battery Energy Storage System (BESS), Power electronics, Dual Active Bridge (DAB), Second-life batteries, Silicon Carbide (SiC).

\section{Introduction}

Demand-side management (DSM) is one of the most promising tools in the next-generation electric energy environment [1] to provide additional system flexibility. DSM can be defined as changes in electric demand by enduse customers from their normal consumption patterns in response to external signals. These signals typically are changes in the electricity price over time, or incentive payments designed to induce lower electricity use when system reliability is at risk [2], [3].

An important obstacle for the implementation of DSM schemes is the reluctance of customers to adapt habits to external signals such as real-time energy prices. This problem is solved if automatic systems are combined with a local battery energy storage system (BESS) which can modulate demand patterns without any inconvenience for the customer [4], [5]. In this line, it has to be highlighted that the use of cost-effective digital technologies (installed at grid and customer-side), is driving the transformation of electric current system into the Smart Grid of the future [6], which in turn, facilitates large-scale integration of renewable energies [7]. Finally, ancillary service markets have been one of the primary sources of revenue for many energy storage projects built to date [8].

In view of these benefits, a DSM system which consists of a software package combined with hardware tools and a low-cost energy storage system [9] has been developed. The BESS is the key element of the designed DSM system as it adapts consumption to energy prices, reducing the electric bills of the customer. Furthermore, the BESS can solve the renewable intermittency problem, compensate reactive power, flatten the load consumption and do functions of peak shaving.

Today, massive utilization of BESS has not yet started, mainly because of the high cost for customers. A possible solution is the use of recovered batteries, such as secondlife EV batteries for example. EV batteries have to be renewed when their total capacity reach $80 \%$ of the original due to aging. These batteries are still operative and could be used for stationary storage purposes. Therefore, increasing EV deployment is providing lowcost second-life batteries, making BESS more attractive for households.

However, these batteries have some drawbacks. For example, in the case of Li-ion batteries, when a single cell is damaged, the whole BESS must be shut down. Sometimes, replacement of damaged cells by the manufacturer is slow and tedious, and the BESS may be inoperative for a long period of time. A second issue is related to uncertain battery properties, due to unknown aging or variety of manufacturers.

The novel BESS design proposed in this paper (Fig. 1) solves these problems. The battery is split in different independent packs, which lets the operation with a high percentage of the total energy even if a battery cell is damaged. Independent packs also enable the use of batteries with different properties, state of health $(\mathrm{SoH})$ or even different chemistries in the same facility. The Main characteristics of the storage system are summarized in Table I. 


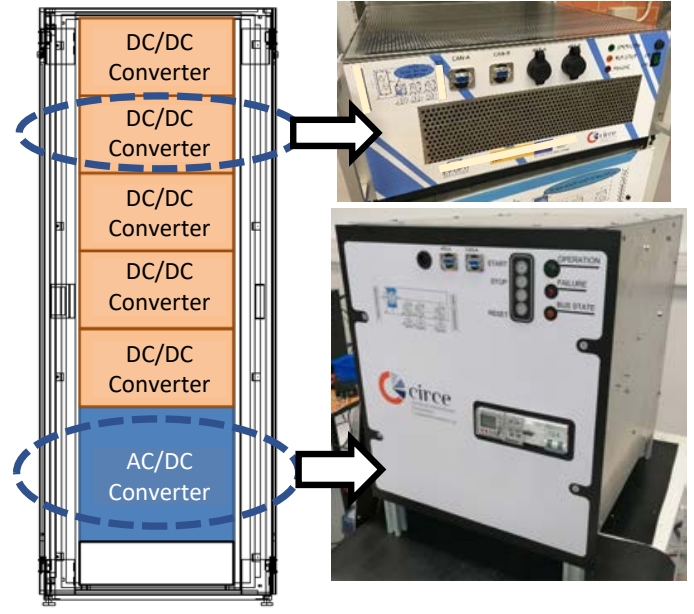

Fig. 1. Global view of the proposed BESS system, in a 19” rack cabinet.

Table I. Technical specifications of the storage system.

\begin{tabular}{|c|c|}
\hline \multirow{2}{*}{\multicolumn{2}{|c|}{ Grid side - AC/DC Converter }} \\
\hline & \\
\hline Main characteristics & $\begin{array}{l}\text { Bidirectional, IGBT technology, multilevel } \\
\text { control, Neutral Point Clamped }\end{array}$ \\
\hline Nominal Power & $50 \mathrm{kVA}$ \\
\hline Connection type & 400 V, 3-phase \\
\hline Voltage tolerance & $\pm 15 \%$ \\
\hline Frequency & $50 / 60 \mathrm{~Hz}, \pm 5 \%$ \\
\hline Power factor & Variable in function of needs \\
\hline Efficiency & 97\% (at rated power) \\
\hline Protections & $\begin{array}{l}\text { Over and under voltage } \\
\text { Over and under frequency } \\
\text { Overcurrent }\end{array}$ \\
\hline Dimension, weight & 19” Sub-rack - 12U x 600 mm, 75 kg \\
\hline \multicolumn{2}{|c|}{ Battery side - DC/DC Converter } \\
\hline Main characteristics & $\begin{array}{l}\text { Bidirectional, isolated, SiC semiconductor, } \\
\text { MOSFET technology, high commutation } \\
\text { frequency, Dual Active Bridge }\end{array}$ \\
\hline Nominal Power & $10 \mathrm{~kW}$ (x5 units) \\
\hline Batteries type & $\begin{array}{l}\text { Any (already tested with Li-ion and Lead- } \\
\text { acid batteries) }\end{array}$ \\
\hline Nominal voltage & $\begin{array}{l}48 \text { Vdc Battery } \\
700 \text { Vdc DC Bus }\end{array}$ \\
\hline Batteries protection & $\begin{array}{l}\text { DC fuses and Software protection over } \\
\text { breaker }\end{array}$ \\
\hline Protections & $\begin{array}{l}\text { Battery overcurrent } \\
\text { PE and battery overtemperature } \\
\text { DC bus overvoltage } \\
\text { Over and under voltage }\end{array}$ \\
\hline Dimension, weight & 19” Sub-rack - 3U x 550 mm, 15 kg \\
\hline \multicolumn{2}{|r|}{ Communications } \\
\hline Internal & CAN \\
\hline $\begin{array}{l}\text { ENERGY BOX } \\
\text { (External SCADA) }\end{array}$ & ModBUS - RS485 \\
\hline Battery BMS & CAN, ModBUS - RS485 \\
\hline
\end{tabular}

\section{Power electronics topology}

The battery charger regulator is connected to the grid by a bi-directional $50-\mathrm{kW}$ three level AC/DC converter that is composed by silicon semiconductors ("Grid side” in Fig. 2) and feeds a 700-V DC bus. Batteries are connected to the DC bus through five isolated bi-directional $10-\mathrm{kW}$ DC/DC converters, using silicon carbide (SiC) semiconductors ("Battery side" in Fig. 2). The chosen battery-side topology with $\mathrm{SiC}$ technology has important benefits over other topologies [10][11], mainly due to higher commutation frequency:

- Reduced converter size (smaller and lighter insulation transformers and filters)

- $\quad$ Reduced switching losses.

The converter design has been optimized to connect different types of battery packs at $48 \mathrm{~V}$, which is a standard voltage used in the market. However, slight hardware and control modifications of the DC/DC converters would allow the integration of batteries with higher voltages and even solar PV systems or V2G chargers.

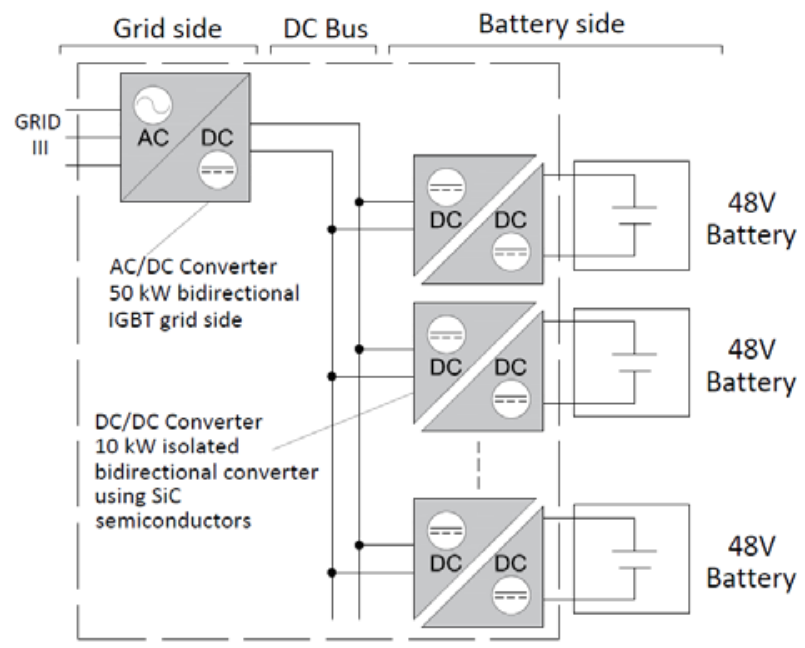

Fig. 2. Block diagram of the battery regulator.

The power electronics topology used in this design allows the use of batteries grouped in packs of different technologies, State of Health $(\mathrm{SoH})$ or capacity. In laboratory, Li-ion and Lead-acid batteries have been tested successfully. These packs can provide up to $10 \mathrm{~kW}$ power and nominal battery voltage is fixed at $48 \mathrm{~V}$. In the case of using lead-acid batteries, the charger incorporates a standardized equalizing process to enlarge the life of the batteries, recovering part of its initial capacity.

The main benefit of using this topology, which permits the combination of different battery packs, is reducing costs and environmental impacts of the system. Cost reduction is obtained from the option of using second-life batteries. Life extension of batteries, re-using and recovering its $\mathrm{SoH}$ through the equalizing process, reduces the environmental life-cycle impact of the system. This multi-technology configuration also allows the operation of each battery according to its requirements (e.g. power limits, state of charge), lengthening battery life and improving the capabilities of the whole system [12].

\section{A. AD/DC topology}

The AC/DC converter, used to exchange power with the electric grid, is designed with a three-level neutral point clamped (NPC) topology, as shown in Fig. 3. 
In comparison with the two level converter, this topology reduces the voltage stress on the IGBTs and their switching losses, increasing the output voltage waveform quality [13]. Current switching ripple is attenuated with a third-order LCL grid filter, which has lower size and price than the first order L filter [14].

Furthermore, this AC/DC converter can operate in the four quadrants, compensating reactive power (V) if needed, even when batteries are not working. This BESS can also regulate its reactive power to support grid operation by means of: constant Q, constant power factor or Q as a function of active power generated/consumed or grid voltage.

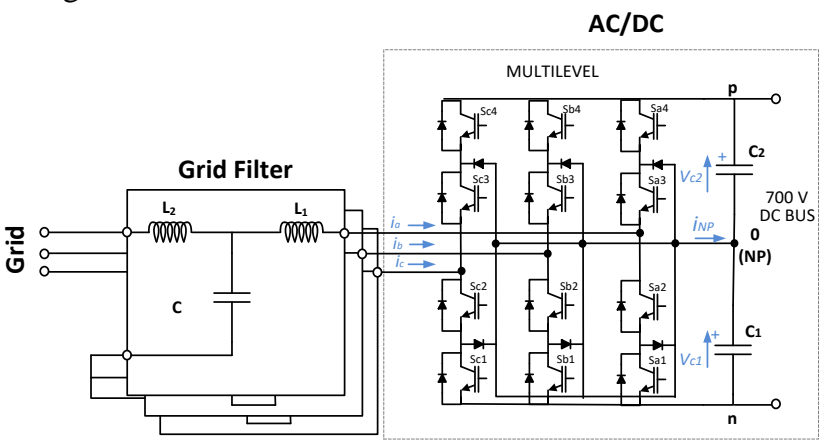

Fig. 3.Three-level neutral point clamped (NPC) AC/DC topology.

\section{B. DC/DC Topology}

A Dual Active Bridge (DAB) DC/DC converter is used to transfer power between the DC bus and the battery (Fig. 4). At the high voltage side, SiC MOSFETs have been used due to the better behaviour at this voltage in comparison with Si MOSFETs, which have been used in the low voltage side. The transformer guarantees the needed galvanic isolation between the battery and the grid side. The high switching frequency, $70 \mathrm{kHz}$, reduces considerably the size of the transformer and therefore the size of the entire converter. To reduce the battery ripple current, a LC filter is placed between the low voltage side of the DAB DC/DC converter and the battery.

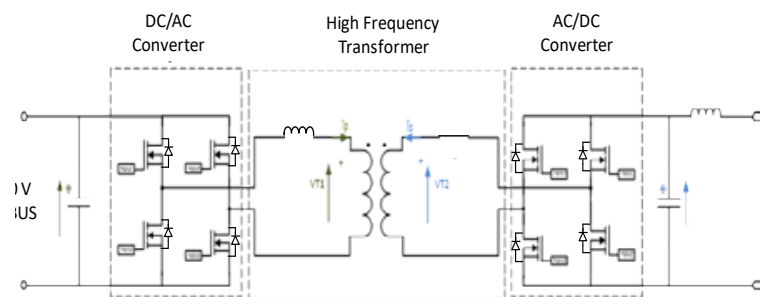

Fig. 4. Dual Active Bridge DC/DC topology.

\section{System management and control}

Fig. 5 shows the three different communication protocols used in the BESS. To manage the system, it has been used a low cost electronic system called Energy Box (EB) [15] which communicates with the AC/DC and DC/DC converters using RS-485 in order to control the power flow through the different batteries and electric grid. This electronic system also provides Ethernet communication, which allows setting and monitoring the BESS by the user. The use of the EB is fundamental for the BESS as a part of an optimal demand-side management system as developed in EV-OPTIMANAGER Project [8], see Fig 5 .

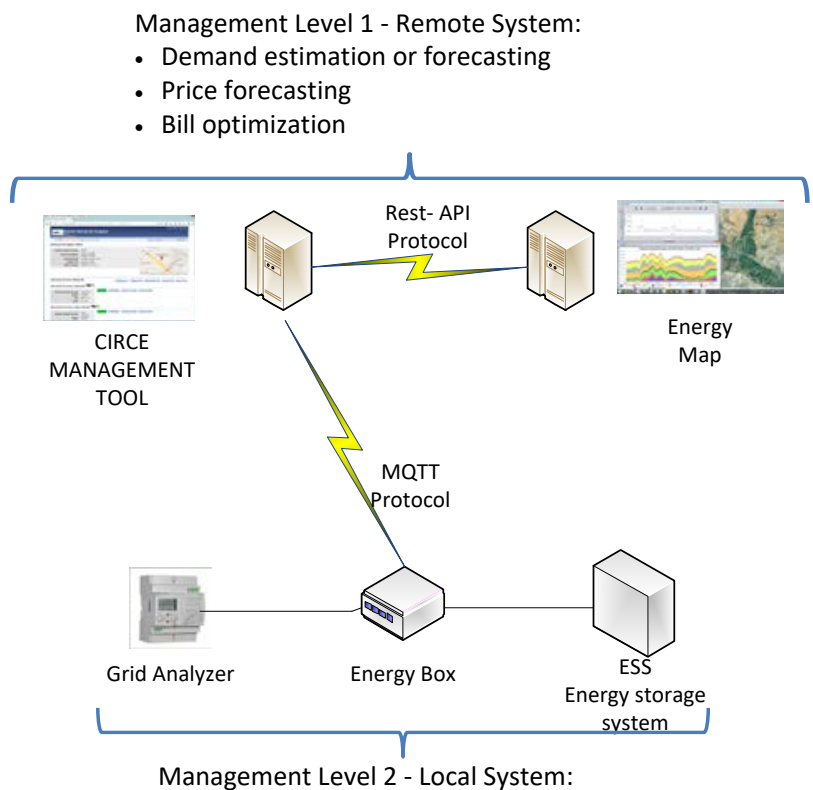

Fig. 5 Global view of the proposed DSM system [9].

Applied to Sudoket Project (Fig 6) the BESS works following the operation setpoints calculated locally in function of the power generated in the photovoltaic panels and the power consumed by the loads.

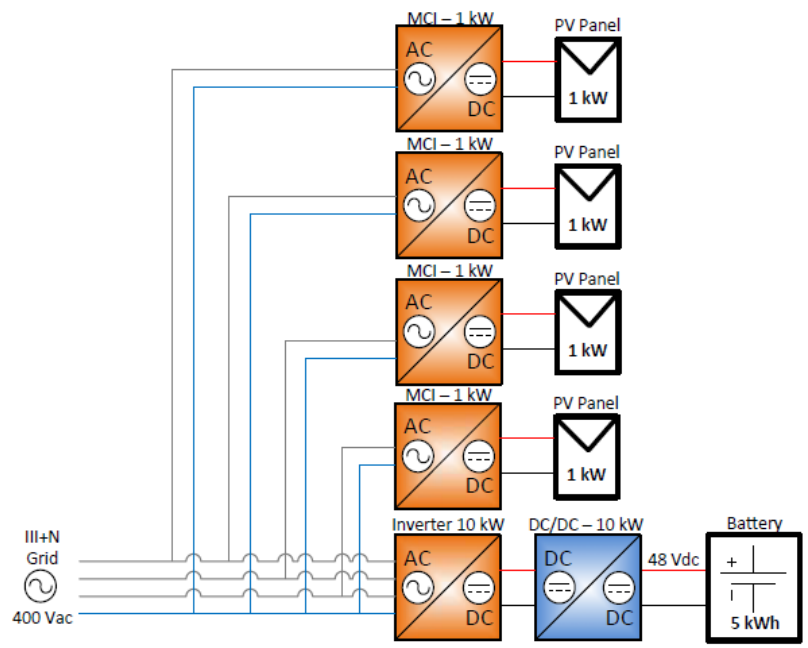

Fig. 6 General block diagram in Sudoket Project.

The AC/DC converter communicates every 2ms with each DC/DC converter to compensate the perturbation at the DC bus produced by rapid changes of power setpoints of the batteries. Furthermore, a watchdog counter has been implemented to monitor if the systems are operative. The communication standard for this purpose is CAN bus due to its robustness and reliability.

The DC/DC system can communicate with the Battery Management System (BMS) using CAN or RS-485, to adapt charging or discharging properties to the state of the batteries, see Fig 7. 


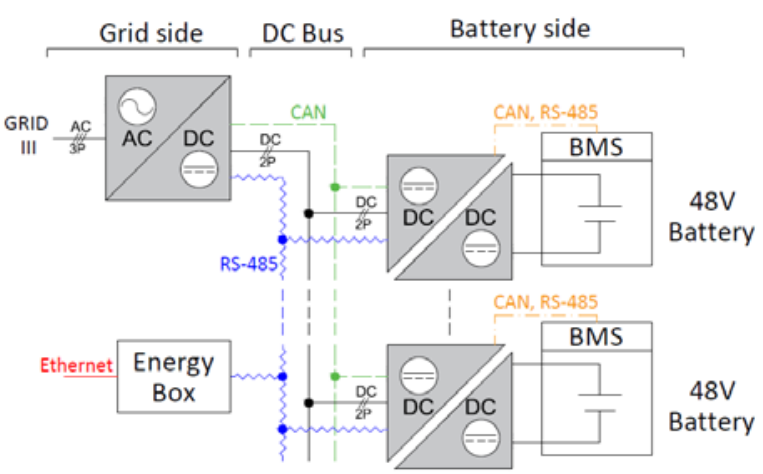

Fig. 7. Communication block diagram of the BESS.

The control block diagram of the battery current is depicted in Fig. 8. The PI closed-loop control ensures a null current error in steady-state and the Feed-Forward increases the time response of the system. Below there is a Lookup table which takes the battery current set-point and gives the PI gain $\mathrm{Ki}$ and phase $\theta$ between the high voltage PWM and the low voltage PWM.

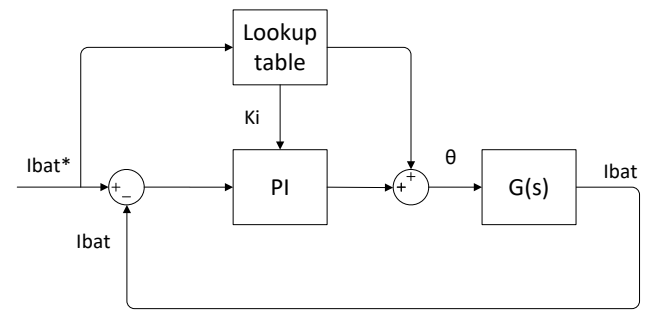

Fig. 8. Battery current control block diagram of the DAB DC/DC converter.

The values of the look-up table have been previously generated simulating the full system in Matlab-Simulink, with a current step of 0.1 A. Fig. 9 illustrates that phase $\theta$ shows a sigmoid curve depending on the input current. With the purpose of linearizing the output, the Ki gain changes depending on the slope of the phase output.

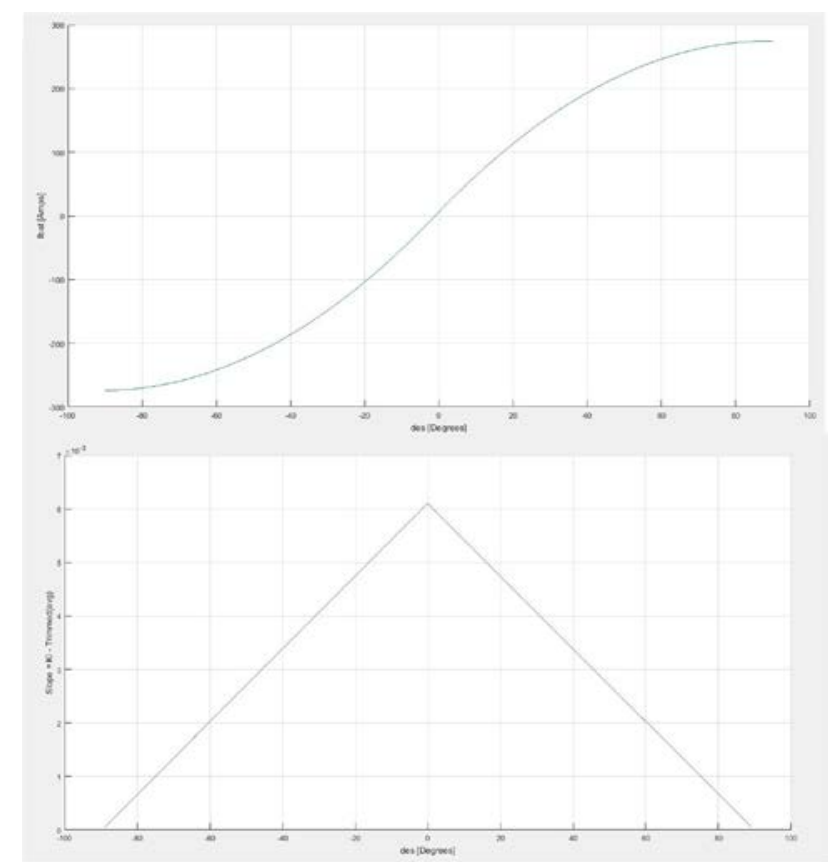

Fig. 9. Lookup table values of PI gain Ki and phase $\theta$ of the FeedForward control.

\section{Modular design}

The battery charger is highly modular, being each converter encapsulated in sub-rack box, which can be placed in a 19" rack cabinet, facilitating modularity, maintenance and expansion of the system with more battery packs and generation technologies. In addition, the DC/DC converter could also be placed closer to the battery than the AC/DC converter, which reduces the length of the greater section wires.

The use of five $10 \mathrm{kVA}$ high-frequency transformers, instead of one $50 \mathrm{kVA}$ low-frequency transformer, leads in the elements weight reduction and division, which makes them more portable, while assuring galvanic isolation. Fig. 10 and Fig. 11 show front and rear views of the AC/DC and DC/DC converter respectively, showing the communications ports, light signals and press buttons at the front side and the input and output terminals the the rear side.

All power, control and communication connections are accessible from the outside of the 19" sub-rack cabinets. This leads to a pick-and-place system, with more interoperability, ease of connection and modularity.

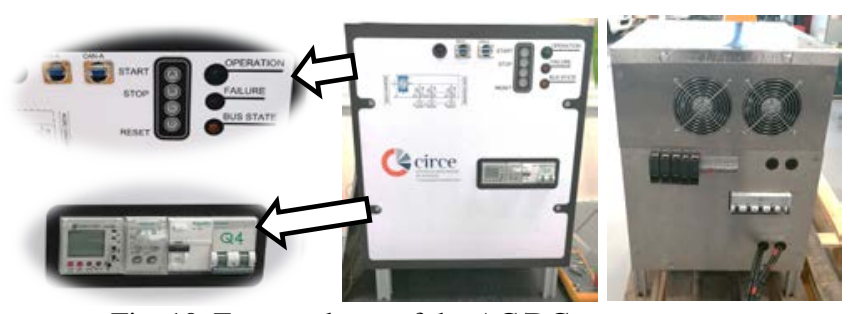

Fig. 10. Front and rear of the AC/DC converter.

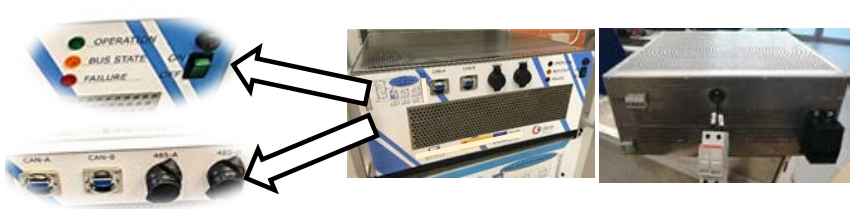

Fig. 11. Front and rear view of the DC/DC converter.

\section{Operation tests}

Several operation tests have been carried out in order to verify the system behaviour, as shown in Fig. 12.

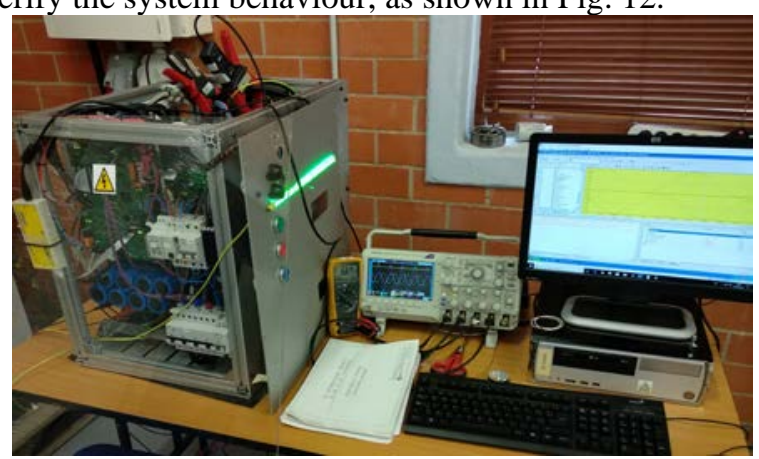

Fig. 12. Laboratory tests in Circe facilities.

Fig 13 shows the phase voltage, the output current and the DC Bus voltage of the AC/DC converter. The grid current Total Harmonic Distorsion (THD) is lower than $1 \%$, measured using a Power Xplorer electric grid analyser, which is well below the limits given by IEC $61000-3-12: 2011$ standard. It is remarkable that this 
current waveform is achieved despite the heavily deformed grid voltage $(\mathrm{Vu})$.

In this case the DC/DC converter was tested connected to the DC Bus and to a Li-ion battery of $48 \mathrm{~V}$. Fig. 14 shows current and voltage waveforms at the high-frequency transformer and the battery current discharging at $-2.5 \mathrm{~kW}$.

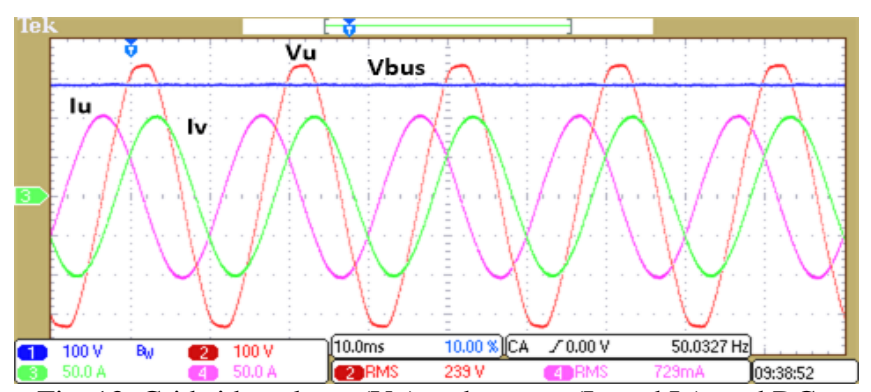

Fig. 13. Grid side voltage (Vu) and current (Iu and Iv), and DC bus voltage (Vbus) waveforms in the grid side AC/DC converter,

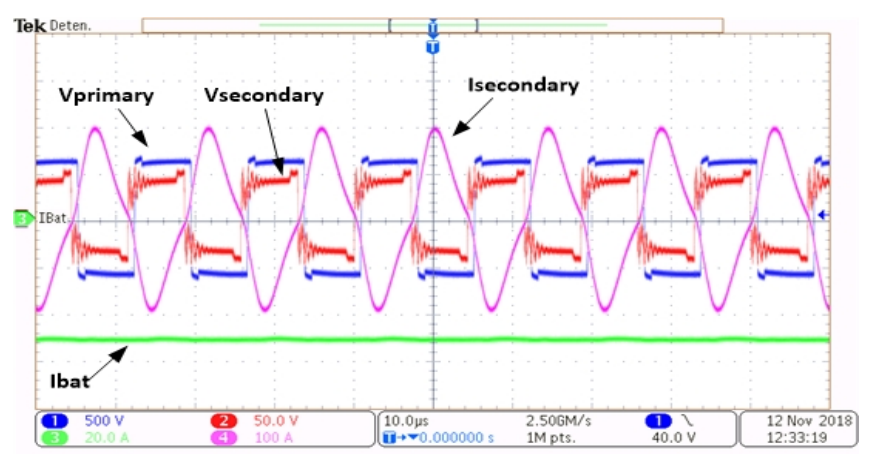

Fig. 14. Voltage and current waveforms of the DC/DC DAB $\mathrm{DC} / \mathrm{DC}$ converter during laboratory tests at $-2.5 \mathrm{~kW}$ (battery

\section{Conclusions}

A novel multi-technology Battery Energy Storage System (BESS) for second-life batteries has been presented, which is able to reduce costs for stationary BESS applications. The system is tested with lead-acid and Li-ion batteries in a demand-side management (DSM) system.

The modular design of the BESS reduces down-times for maintenance and reduces weight and size of each battery module, while making them portable.

SiC semiconductors in the DC/DC converters allow 70 $\mathrm{kHz}$ switching frequency, which reduces filters and transformers cost and size.

Ongoing work is considering integration of renewable generation and V2G directly at the DC bus. Foreseen developments consider multiple BESS on the DC-Bus and the development of a 4-wire grid side, which enables balancing services in unbalanced systems.

\section{Acknowledgement}

This paper shows the results of a thorough research and work carried out in the Sudoket Project (SOE2/PI/EO677). during laboratory tests at $50 \mathrm{kVAr}$. discharge).

This project is supported by the Interreg Sudoe Proggramme through the European Regional Development Fund (ERDF).

\section{Interreg $\$$ Sudoe

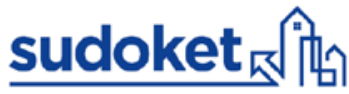

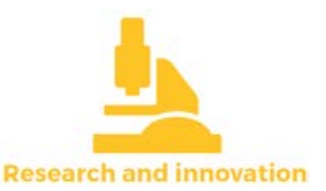

\section{References}

[1]

[2]

S. H. ; S. H. ; K. Sezaki, "Development of an Optimal Vehicle-to-Grid Aggregator for Frequency Regulation,” IEEE Trans. Smart Grid, no. 1, p. 1, 2010.

D. US Dept. Energy, Washington, Benefits of demand response in electricity markets and recommendations for achieving them. 2006.

M. H. Yaghmaee, M. Samadi Kouhi, A. Saeedi, and M. Zabihi, "Demand side management controlling with personalised pricing method," CIRED - Open Access Proc. J., vol. 2017, no. 1, pp. 2666-2669, 2017.

K. Cho, S. Kim, J. Kim, E. Kim, Y. Kim, and C. Cho, "Optimal ESS Scheduling considering Demand Response for Electricity Charge Minimization under Time of Use Price Key words,” Int. Conf. Renew. Energies Power Qual., no. 14, pp. 264-267, 2016.

G. Giaconi, D. Gunduz, and H. V. Poor, “Optimal DemandSide Management for Joint Privacy-Cost Optimization with Energy Storage,” no. October, pp. 265-270, 2017.

A. Gomez-Exposito et al., "City-Friendly Smart Network Technologies and Infrastructures: The Spanish Experience," Proc. IEEE, vol. 106, no. 4, 2018.

R. Tisseur, F. De Bosio, M. Fantino, P. Torino, and P. Torino, "Optimal Scheduling of Distributed Energy Storage Systems by Means of ACO Algorithm," 2016.

A. Eller and A. Dehamna, "Executive Summary : Market Data : Ancillary Service Markets for Energy Storage Spinning Reserves, Non-Spinning Reserve Capacity , Frequency Regulation, and Volt / VAR Support : Global Market Analysis and Forecasts," 2017.

G. Fernández et al., "Optimal demand-side management with a multi-technology battery storage," in International Conference on Renewable Energies and Power Quality (ICREPQ'18), 2018, no. 16, pp. 1-5.

H. Zhao Yu, J. and Ling, J., "Finite element analysis of Cymbal piezoelectric transducers for harvesting energy from asphalt pavement,” J. Ceram. Soc. Japan, 118 909-915, 2010. J. Agarwal, "Assessing the Impact of SiC MOSFETs on Converter Interfaces for Distributed Energy Resources,” IEEE Trans. Power Electron., vol. 24, no. 1, 2009.

S. Rothgang, T. Baumhöfer, H. van Hoek, T. Lange, R. W. De Doncker, and D. U. Sauer, "Modular battery design for reliable, flexible and multi-technology energy storage systems,” Appl. Energy, vol. 137, pp. 931-937, 2015.
J.-H. Cho, N.-J. Ku, J.-T. Han, R. Kim, and D.-S. Hyun, “A simple control method for neutral-point voltage oscillation reduction of three-level Neutral-Point-Clamped inverter," in IECON 2013 - 39th Annual Conference of the IEEE Industrial Electronics Society, 2013, pp. 304-309.
H. Azani, A. Massoud, L. Benbrahim, B. W. Williams, and D. Holiday, "An LCL filter-based grid-interfaced three-phase voltage source inverter: Performance evaluation and stability anaylsis," in 7th IET International Conference on Power Electronics, Machines and Drives (PEMD 2014), 2014, pp. $1-6$.

[15] A. Andolsek, A. Zocchi, M. P. Nemce, J. Bruna, A. Gómez, and M. A. Oliván, "Flexibility and optimization services validation in a microgrid,” in CIRED Workshop - Ljubljana, 2018. 